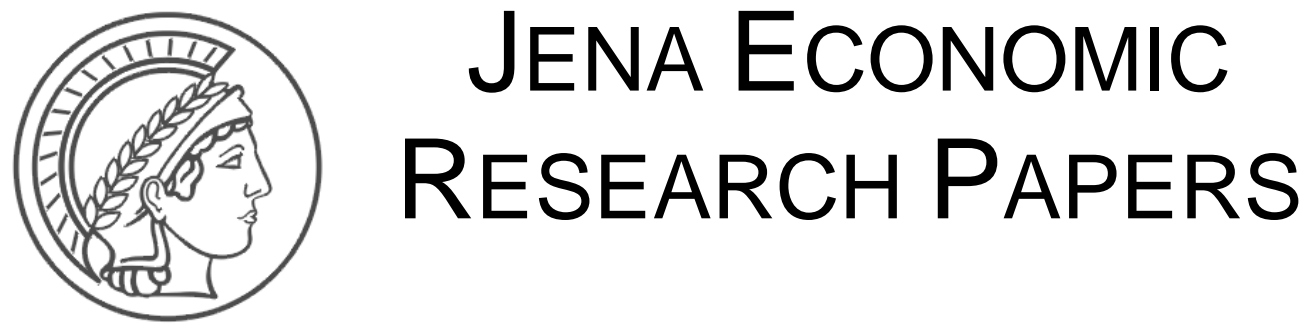

\# 2007 - 099

\title{
(Non-) Behavioral Economics \\ - A Programmatic Assessment -
}

\author{
by \\ Werner Güth
}

www.jenecon.de

ISSN 1864-7057

The JenA ECONOMIC ReSEARCH PAPERS is a joint publication of the Friedrich Schiller University and the Max Planck Institute of Economics, Jena, Germany. For editorial correspondence please contact m.pasche@wiwi.uni-jena.de.

Impressum:

Friedrich Schiller University Jena

Carl-Zeiss-Str. 3

D-07743 Jena

www.uni-jena.de

(c) by the author.
Max Planck Institute of Economics

Kahlaische Str. 10

D-07745 Jena

www.econ.mpg.de

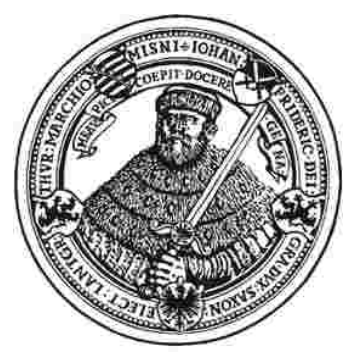




\title{
(Non-) Behavioral Economics
}

\section{- A Programmatic Assessment -}

\author{
Werner Güth
}

December 3, 2007

\begin{abstract}
Economic theory has evolved without paying proper attention to behavioral approaches, especially to social, economic, and cognitive psychology. This has recently changed by including behavioral economics courses in many doctoral study programs. Although this new development is most welcome, the typical topics of the behavioral economics courses are not truly behavioral. More specifically, we question whether neoclassical repairs or game fitting exercises as well as more or less mechanic adaptation processes qualify as behavioral approaches. To avoid criticizing without offering alternatives, we suggest some truly behavioral concepts, especially the satisficing approach.
\end{abstract}

JEL classification: A11, B41, B52, C72, C91

Keywords: (Un)Bounded rationality, Satisficing, Learning, Experimental and Behavioral Economics 


\section{Introduction}

Homo oeconomicus is assumed to know his preferences and choice set and to solve his optimization task, regardless how difficult this is. Which room does this leave for behavioral approaches? One possibility is to specify preferences by empirical findings on people's motivation and emotions in given decision environments. This implies the usual inference problems when having to deduce motivations and emotions from pure choice data, similar to the revealed preference approach (see Samuelson, 1938, and Varian, 1992). Similarly, one can rely on empirical research when trying to assess which choice alternatives exist and are actually considered. In case of taboos, one could either consider taboo choices as clearly less preferred or directly exclude them from the choice set. In these ways one can and always has paid attention to empirical research in economics. We will discuss whether a truly behavioral approach can rely on assumptions like

- given preferences,

- given choice sets, and

- individual optimality (in the sense of selecting a choice alternative which, according to one's preferences, is not worse than any other possible choice).

We will refer to explanations, keeping up these three assumptions, as neoclassical repairs when applied to individual choice tasks and as game fitting when applied to situations involving others.

Compared to the traditional rational choice approach in economics the tradition in evolutionary biology has been that of path dependence in the sense of the Darwinian principles of variation, retention and selection. Again the rational choice perspective does not completely rule out such path dependence, e.g. in the sense that our preferences for food have evolved from our vitamin needs (see Samuelson, 2001, and Berninghaus et al., 2003). More generally, one may endogenously derive preferences as well as choice sets 


\section{Jena Economic Research Papers 2007-099}

by appropriate evolutionary exercises. But more basically, the distinction remains: whereas in evolutionary biology we presently choose what we do since it has been successful before, i.e., behavior is determined in the shadow of the past, in traditional economics behavior is selected because of its anticipated consequences, i.e., in the shadow of the future. Although our behavior is very much path dependent, denying more or less all forward looking deliberation as many simple minded adaptive processes, another major topic in the behavioral economics program, means to throw out the baby with the bath water. Homo sapiens is definitely adapting but not mechanically and is also deliberating but can do so at best in boundedly rational ways.

As for neoclassical repairs and game fitting, we will discuss whether and, if so, which adaptive processes can be justified as behavioral research. That this is questionable for some adaptive dynamics is obvious since, for instance, replicator dynamics deny any kind of forward looking deliberation which is so typical for homo sapiens and, in fact, for most mammal species (see de Waal, 2000). Other adaptation dynamics rely on weak cognitive demands, e.g. reinforcement learning on the idea that what was good in the past should be good in the future, or actually ask for rationality as best reply dynamics. This already illustrates that most of these single and simple minded adaptation processes will hardly qualify as truly behavioral contributions.

But we do not only want to criticize but also suggest other approaches to substitute or at least supplement the - in our view - questionable parts of the recently established behavioral economics programs. More specifically, we will elaborate more formally the satisficing approach and discuss how it can be empirically, actually experimentally validated. So far satisficing with its component processes, namely aspiration formation, search for satisficing alternatives, aspiration adaptation, which may have to be employed repeatedly, provides mainly an intuitive and natural language for describing how we make a decision. To derive specific predictions based on the satisficing approach requires to elicit aspirations and how they are adapted in the light of feedback information when searching for satisficing alternatives. Our attempt to formalize the satisficing approach renders it more applicable but also allows for disconfirming evidence. 
Without claiming completeness, we also review other - in our view - truly behavioral ideas, regardless whether or not they qualify as boundedly rational. Behavioral economics tries to predict and explain economic behavior, whether or not it is adequate. One may, for instance, analyze routine behavior or conformative decision making (following social norms or conventions). Here importing the categories of traditional into behavioral economics may not help to understand how we behave but can rather lead to a dead end or just transform the question "why such behavior?” to asking "why such preferences and choice sets?” When not just exploring “how do people behave?” but when asking what bounded rationality should mean - "how should we behave, given our cognitive limitations?” - one may require specific decision goals (but no well-behaved preferences) and a few relevant (but not necessarily all) decision alternatives. But even then the categories of the homo oeconomicus approach seem inadequate and even misleading.

In section 2, we discuss "neoclassical repairs” (Güth, 1995) or, in case of strategic interaction, "game fitting". Section 3 is dedicated to adaptive processes of decision making. In section 4, we will illustrate how to specify the satisficing approach. Section 5 tries to answer what else, i.e., other than satisficing, is truly behavioral and section 6 concludes.

\section{Fitting and repairing the rational choice model}

Rather than arguing purely conceptually let us consider a specific decision task, namely that of a responder in an ultimatum game with a commonly known positive pie size, i.e., a positive monetary reward $p$ which the proposer and the responder can share. If the rules of the ultimatum game only allow for offers $o$ with $0<o<p$, the responder, after being informed about the offer o, has a simple choice between "acceptance” (yielding him $o$ and $p-o$ for the proposer) or “rejection” (leaving both players with 0-payoff). 


\section{Jena Economic Research Papers 2007-099}

Now assuming that the responder belongs to the species "homo oeconomicus" rather than "homo sapiens" requires responder preferences. Let us start by assuming that responder preferences are determined by responder earnings, i.e., the responder prefers the alternative yielding him a higher payoff. Since all offers $o$ are positive, this means that the responder will always accept, irrespective how small the offer $o$ is in comparison to $p$. After Güth et al. (1982) and many subsequent experiments (see for a recent survey Camerer, 2003), we all know that this is not true: at least in the range $\mathrm{o}<\mathrm{p} / 3$ more offers are rejected than accepted (see Güth et al., 2003 and 2007, for rather large data sets).

Repairing the homo oeconomicus model means to adjust it in a way rendering observed behavior optimal. If additionally the way of "repairing” is intuitively appealing, this even may be convincing, at least to someone used to rely on the rational choice approach. In the case at hand, the obvious idea is to rely on social preferences, e.g. by assuming that the responder is not only interested in his own earnings but also in a fair distribution of $p$. Recently this is often described by saying that the responder is inequality averse ${ }^{1}$ (see Bazerman et al., 1989, Bolton, 1991, Bolton and Ockenfels, 2000, Fehr and Schmidt, 1999). It is obvious how this can render offers o in the range $o<p / 3$ unacceptable for a rational but sufficiently inequality averse responder. This illustrates how repairing the responder model by adding other regarding concerns (about how fairly the pie $p$ is distributed) can fit the rational choice prediction to what has been observed experimentally.

It clearly makes sense that responder participants in an ultimatum experiment care about how fair the offer $o$ is. But does it help much to say "many responders are sufficiently inequality averse" rather than "responders often reject unfair offers"? If inequality aversion as, for instance, measured by the highest rejected offer $o$ can also explain behavior in other experiments (see Bolton and Ockenfels, 2000, for such an attempt), such a neoclassical repair could be quite an achievement. Nevertheless even then, from a behavioral perspective, it would not adequately capture how homo sapiens responders

\footnotetext{
${ }^{1}$ What one essentially does is to rely on equity theory (Homans, 1961) and to allow for a smooth tradeoff between own material payoff and equity concerns.
} 


\section{Jena Economic Research Papers 2007-099}

generate their choice. We are not established with well-behaved preferences telling us how to trade off own payoff with inequality but rather have to make up our mind about what we prefer. What repairing the responder model provides is thus an as-if (rational choice) explanation but not a description how homo sapiens responders proceed to determine behavior.

Could this be the reason why the widely used idea of inequity aversion has recently been questioned (see Binmore and Shaked, 2007)? One should be aware that the same criticism applies to risk aversion. Here one might argue that, in view of the many risks of life, the obvious way to choose between two lotteries with moderate monetary prizes, e.g. in the range from 0 to 100 euros, is according to their monetary expectations. But when letting participants decide between the simple lottery offering 1 euro or 99 euros with probability $1 / 2$ each and the sure win of, for instance, 47 euros many will prefer the sure win. Explaining this by sufficiently strong risk aversion provides at best a reasonable asif explanation of choice making under risk and also qualifies as a neoclassical repair. The reason why one hardly objects to "repairing via risk aversion" is not that this is less debatable but only that economists are much more used to apply the idea of risk aversion.

Before concluding our discussion of "fitting and repairing", let us briefly mention that such exercises become much more questionable in interactive decision making. It is, for instance, a ridiculous aspect of nearly all (game) theoretic auction studies that they do not only assume that idiosyncratic risk attitudes are commonly known but also more often than not that they are the same for all competing bidders. Of course, one will object that this is just a simplification and that one can also study situations with private information about risk attitudes. What we want to stress nevertheless is that repairing by idiosyncratic attitudes towards risk and/or inequity will usually rule out common knowledge of such attitudes. Neglecting this obvious asymmetry in information, leads to debatable rational choice exercises as in auction theory. Accepting that such attitudes are private information on the other hand complicates the exercises so much that they lose all their behavioral appeal. 


\section{Evolving, learning, adapting rather than deliberating}

Compared to the earlier discussion of learning theory in psychology (Bush and Mosteller,1951), the high season of evolutionary and learning studies in economics is rather recent (see Hammerstein and Selten, 1994, Samuelson, 2001, Weibull, 1995). But the basic idea is an old one ${ }^{2}$. To assess the behavioral appeal of some well-known adaptive processes, the following table lists for each of them

- what the decision maker has to know about his decision environment,

- which feedback information the process requires,

- which degree of rationality the process presupposes.

\begin{tabular}{|l|l|l|l|}
\hline Type of adaptation & $\begin{array}{l}\text { Awareness of } \\
\text { decision } \\
\text { environment }\end{array}$ & $\begin{array}{l}\text { Feedback } \\
\text { information }\end{array}$ & Rationality request \\
\hline replicator dynamics & none & none & no deliberation at all \\
\hline $\begin{array}{l}\text { reinforcement } \\
\text { learning }\end{array}$ & $\begin{array}{l}\text { of own choice } \\
\text { alternatives }\end{array}$ & $\begin{array}{l}\text { about own past } \\
\text { success }\end{array}$ & $\begin{array}{l}\text { assumes that what } \\
\text { was good in the } \\
\text { past, will be good in } \\
\text { the future }\end{array}$ \\
\hline imitation & $\begin{array}{l}\text { that own and others’ } \\
\text { choices are the same }\end{array}$ & $\begin{array}{l}\text { about own and } \\
\text { others' past success }\end{array}$ & $\begin{array}{l}\text { assumes that what } \\
\text { has been good for } \\
\text { others in the past, } \\
\text { will be good for } \\
\text { oneself in the future }\end{array}$ \\
\hline directional learning & full & about past outcome & $\begin{array}{l}\text { full rationality in } \\
\text { retrospective } \\
\text { decision analysis }\end{array}$ \\
\hline best reply dynamics & full & about others' past & rational forward \\
\hline
\end{tabular}

\footnotetext{
2 Already Cournot (1938) justified his duopoly solution from which no seller would want to deviate unilaterally, by best-reply dynamics. Furthermore, the population interpretation of mixed strategy equilibria by Nash (1950) seemed to suggest an evolutionary justification of such solutions. And there was always the argument around that what we prefer, e.g. to eat, had to be survival enhancing.
} 
\begin{tabular}{|l|l|l|l|}
\hline & behavior & looking deliberation \\
\hline
\end{tabular}

Clearly, replicator dynamics are at odds with the usual idea that economic decisions are deliberated by trying to assess their future consequences. Denying all anticipation essentially means to deny any cognition and any difference between homo sapiens and insect species. Reinforcement learning (see the corresponding chapter in Camerer, 2003) also denies any forward looking deliberation and mainly relies on the "law of effect", we repeat more often what has been better in the past. We do not at all deny that we sometimes submit to the "law of effect": if nothing is known about how choices affect success, we hardly have a better way of reacting to feedback information. For instance, when confronting a completely new decision environment about which one hardly knows anything, we may very likely begin by reinforcement learning. However, when becoming more experienced due to repeatedly deciding, we typically try to mentally represent the decision problem in the light of what has been experienced so far. What this means is that we do not remain to be as structurally uninformed as in the beginning. This either questions that we continue to be reinforcement learning as typically assumed in its single minded exercises (e.g. Roth and Erev, 1999) or denies any feedback information from which we can infer how to mentally represent the decision environment.

Imitation dynamics basically require some (belief in) similarity of own and others' decision tasks justifying the cognitive assumption that what has been good for others in the past should be good for oneself in the future. Applying this dynamics without repeatedly checking in the light of information feedback, the adequacy of this assumption can lead us astray: a seriously liquidity constrained seller, for instance, must try to avoid transitory losses much more than a competitor without such restriction. Thus a risk which the latter can accept may be fatal for the former. Similarly, there may be choices like market entry decisions (see Selten and Güth, 1982) where few can enter profitably but not all. Thus simply imitating what others did can be a serious mistake. Nevertheless we often imitate successful others (see Huck et al., 1999 and 2000, for experimental evidence where, however, often the market game had been symmetric even when no structural information was provided). In our view, imitation has quite some behavioral appeal 


\section{Jena Economic Research Papers 2007-099}

although it is again questionable whether we are such single minded imitators as supposed in most studies of imitation learning (e.g. Vega-Redondo, 1997).

Directional learning (e.g. Selten and Buchta, 1994, and with some "repairing”, Ockenfels and Selten, 2005) requires cognitive awareness how own choice determines own success but avoids the problem of strategic interaction: by assuming only retrospective decision deliberations in the light of feedback information, telling more or less what others have done, others do not have to be predicted. Rather than demanding that one can find out the best choice in the past situation, it limits its applicability to cases where one can unambiguously assess one directional change (the choice set has to be ordered such that directional changes make sense) as superior to what one has actually done and excludes an adaptation in the wrong directions. There has been some experimental validation of reinforcement (e.g. by Avrahami et al., 2001 and 2005) but also some failures (e.g. Dittrich et al., 2005). But compared to best reply dynamics, which requires fully rationally forward looking deliberation and thus relies only on belief (what others choose) learning, its behavioral appeal is undeniable. But it also may lose importance when, due to more and more information feedback, people become more and more experienced (in the non-confirming study of Dittrich et al., the participants play 250 rounds of the same game and, since they confront two closely related games, altogether 500 rounds).

\section{Satisficing and aspiration formation as well as adaptation}

Our criticism is that neither the bottomless Pandora-Box of neoclassical repairs (including prospect theory and other variants of non-expected utility) and game fitting ideas (like psychological game theory, quantal response equilibria etc.) nor the propagation of single and simple minded adaptation dynamics, imported (partly after being discarded as behaviorally inadequate) from other disciplines, hardly qualify as truly behavioral approaches. In our view, the new tradition of behavioral economics also requires a new toolbox. There is nothing truly behavioral when maintaining that people optimize $^{3}$ more or less complex "utilities", that interacting parties will be able to derive

\footnotetext{
${ }^{3}$ Possibly being aware how they fail to implement what they want to choose (as supposed by quantal response equilibria, Mc Kelvey and Palfrey, 1995).
} 


\section{Jena Economic Research Papers 2007-099}

equilibria what may require circular reasoning, or when claiming quite the opposite, namely that people are more or less dumb, as supposed by some of the popular adaptation dynamics.

One could argue that one should not discard traditional tools when they cannot be substituted. Quite often it is claimed that psychology offers many interesting but rather fragmented ideas whereas economics with its neoclassical jargon and game theoretic foundation appears much more systematic. Clearly, a unifying framework (see Güth, 2000, for such an attempt) is quite an achievement. But when allowing for all sorts of repairs and (game) fitting ideas or simple minded adaptation dynamics nothing is gained by employing the rational choice or adaptation jargon simply because it has been downgraded to a language rather than a theory. Buying this more and more flexible language offers no structural information how people behave.

But does there really exist no alternative for the rational choice or mechanic adaptation approach? In our view, the situation is not so hopeless. Especially, but not only (see section 5 below), the satisficing approach (Simon, 1955) can be more fully developed and thus become applicable. Compared to the traditional tools it relies on concepts like aspirations, search for something satisficing and adaptation of aspirations (see Sauermann and Selten, 1962) which we employ in our daily decision making. But except for a few more specific studies (e.g. Bolle, 1979, Seale and Rapoport, 1997 and 2000), it more often than not has been restricted to providing an intuitive and natural language for describing choice making.

Now trying to outline a generally applicable theory of satisficing would be utterly naïve. It not only would have to be too simplistic but also outrageously speculative. In our view, further developments should be based on gradual attempts of generalizing the satisficing hypothesis where each step of this generalization process should be substantiated by empirical research to avoid pure speculation, based at best on introspection but without proper empirical confirmation. 
But how can we render the satisficing approach more applicable? The situation is not so different from the rational choice approach which without specification of preferences does not predict anything specific. Similarly, satisficing has hardly any or no informative content when not knowing aspirations. But whereas asking for aspirations is natural and can be done convincingly, e.g. by questionnaire or experimental studies, asking for preferences is more debatable. In our attempt to render the satisficing approach applicable for some specific choice tasks, we will therefore assume that aspirations can be elicited after having been formed and possibly adapted. Similar to the revealed preference approach, one can, of course, also try to infer aspirations by observing choice behavior (see, for instance, Seale and Rapoport, 1997 and 2000) but this will not be elaborated or discussed in our brief and therefore necessarily very specific analysis. Furthermore, we will try to describe our ideas for a very simple task rather than developing it in more generally.

Consider an investor with an interest free credit line $E(>0)$ who can refrain from using $E$, i.e., leave some money idle, invest it into a risk free bond with repayment rate $r>1$, and/or in a risky assent whose return rate is $l$ with $0 \leq l<r$ in the bad state $B$ and $h$ with $h>r$ in the good state $G$ of the world. Leaving money idle is definitely suboptimal since investing in the bond is better due to $r>1$ (= the return rate of idle money). Although we do not claim that people always avoid suboptimal choices, satisficing theory is mostly seen as the core idea of bounded rationality according to which obviously suboptimal choices should be avoided. We can therefore assume that, if $I$ with $0 \leq I \leq E$ is invested in the risky asset, the remainder $E-I$ is used for the risk free bond.

Let us assume that the investor has formed an aspiration on how much to gain in the bad and good state of the world and denote these aspirations by $A_{b}$ and $A_{g}$, respectively. Satisficing means to choose an investment I satisfying them both, i.e., $(E-I)(r-1)+I(l-1) \geq A_{b}$ and $(E-I)(r-1)+I(h-1) \geq A_{g}$ or 
$\frac{E(r-1)-A_{b}}{r-l} \geq I \geq \frac{A_{g}-E(r-1)}{h-r}$.

For a given aspiration profile $\left(A_{b}, A_{g}\right)$, we refer to this interval as its satisficing set. The requirement that this interval for $\mathrm{I}$ is non-empty can be endangered by too ambitious aspirations (a too high level of $A_{b}, A_{g}$, or both). If the interval is non-empty, it may be very large. In this case, one could increase one aspiration, $A_{b}$ or $A_{g}$, without having to decrease the other. Aspiration profiles, defining non-empty satisficing sets, are satisfiable. "Optimal” aspiration profiles $\left(A_{b}^{*}, A_{g}^{*}\right)$ have to satisfy

$\frac{E(r-1)-A_{b}^{*}}{r-l}=I^{*}=\frac{A_{g}^{*}-E(r-1)}{h-r}$.

More generally, an aspiration profile defining a state-specific aspiration for each state of nature, is optimal when it is impossible, without endangering satisfiability, to increase the aspiration for one state and maintain those for the other states. There exist many “optimal” aspirations profiles $\left(A_{b}^{*}, A_{g}^{*}\right)$ prescribing different investments $I^{*}$ and differing in how they trade off how much is gained in the bad versus the good state. Here we do not want to propagate this prior free (we did not introduce prior probabilities specifying how likely the two states are) and thus, compared to expected utility theory, more basic optimality concept (see Güth, 2007). Although learning by own experience or from others may let people adapt their aspirations in the direction of some "optimal" aspiration profile, people will usually find it difficult to derive such optimal investments (with more states of the world deriving the satisficing set, an intersection of linear half-spaces, see Güth, 2007, can be quite demanding). The main purpose of the little exercise is to demonstrate that, once aspirations are given, one can employ them to derive unambiguous predictions and that optimality can be viewed as a special case of bounded rationality (the set of optimal aspiration profiles is a subset of the satisfiable aspiration profiles).

What does an aspiration profile actually imply? The idea is that one will not stop searching for a satisficing choice alternative until one finds something satisfactory. If this search takes too long, one often will adapt one's aspirations during the search process. 


\section{Jena Economic Research Papers 2007-099}

The most prominent paradigm for exploring the interaction of the two basic processes of aspiration formation and adaptation and searching for a satisficing choice alternative is the secretary search problem (Seale and Rapoport, 1997 and 2000): choice candidates show up one after the other in a random order and one stops search by selecting the present candidate (in case of no recall, i.e., any former candidate is lost), not knowing how good the remaining (not yet seen) candidates would have been. Aspiration formation here means that one first looks at several candidates without any intention to select them (Güth et al., 2006, refer to this as an aspiration for experimentation) and then forms an aspiration level specifying how good an eligible candidate has to be. When going on screening candidates, one may, of course, adapt this aspiration in the light of the quality of the newly screened candidates showing that searching for something satisficing and adaptation of aspirations usually interact.

What does it mean to miss or satisfy an aspiration? The latter just says that one is satisfied with the own choice in the sense that one has achieved what one has hoped for. The more difficult case is when one's choice does not satisfy the formed aspiration. In the secretary problem imagine, for instance, that the overall best candidate has been one of the candidates in the initial phase of experimentation, that the best candidate has determined the aspiration level and that this aspiration level has not been adapted during the later unsuccessful search. Thus what the decision maker finally gets is less than what he has hoped for and experienced as a feasible but missed choice alternative. In our view, frustration from achieving less than aspired questions one's well-being and, as a consequence thereof, even one's trust in the own competence. In the portfolio selection task, one may even have planned own expenditures based on one's aspiration profile. Here missing one's aspiration could make it necessary to change one's plans how to spend the expected gain, what can be quite unpleasant.

As for (cardinal) utilities, it is not obvious how to observe aspirations empirically. Let us briefly discuss some experimental methods of eliciting aspirations. The traditional method (see, for instance, Seale and Rapoport, 1997 and 2000, who study secretary problems) is similar to the revealed preference approach of traditional microeconomics: 
one tries to infer aspirations from choice data. When having seen and not taken a candidate in the secretary search task, considering and discarding a financial investment I, etc., one can certainly assess lower bound estimates for aspirations. This is suitable if it provides sufficiently precise aspirations. But more often than not (this is similar to the impracticability of the revealed preference approach) this is quite complicated and problematic.

An easy but debatable alternative is to simply ask for aspirations in an experiment (Güth, 2007, reviews some experimental studies eliciting aspirations as cheap-talk data in the sense that stated aspirations do not have any direct outcome effects). Another possibility is to incentivize the specification of aspirations, e.g. by a payment scheme according to which one does not earn what one has actually gained in an experiment but only what one has aspired whereas when having missed one's aspiration, one gets only the next lower satisfied aspiration (see Berninghaus et al., 2006) or even no monetary payment at all (see Güth et al., 2007). Note that employing such incentive schemes does not only render the satisficing hypothesis but also prior-free optimality experimentally testable and falsifiable. Altogether this shows that one can assess aspirations empirically (at least experimentally) in various ways which all have their drawback but also offer chances to understand better how one forms and adapts aspiration levels before and/or during search for a satisficing choice.

\section{What else is truly behavioral?}

Interpreting "truly behavioral" as more general than "boundedly rational" allows for a wide variety of ideas, discussed in the literature, like

- "heuristics” (e.g. Gigerenzer and Todd, 1999) meaning that one follows some easily implementable mode of behavior without analyzing more or less thoroughly why and when this is reasonable ${ }^{4}$,

\footnotetext{
${ }^{4}$ One more debatable heuristics is the so-called $1 / \mathrm{N}$ heuristic where $\mathrm{N}$ is the number of different financial investments, meaning that one invests the same amount in all N options (Gigerenzer, 2000). In the financial investment task it would imply to use the available amount equally for bond and risky asset (viewing idle money as a disregarded option).
} 
- “routines", i.e. (possibly after some initial exploration), one follows a standard rule without reflecting (anymore) whether some changes in the environment suggest something different, see, for instance, the early account of routines used in enterprises, reported by Cyert and March (1964),

- similarity considerations in the sense that, when encountering a new decision problem, one tries to apply successful modes of behavior for other "similar" tasks where one may have to rely on qualitative resemblance as well as on quantitative similarity operations (e.g. Rubinstein, 1998),

- cognitive psychology informing us how we mentally represent a decision task and use it to reason how to behave as well as

- other ideas (mental accounting ${ }^{5}$, e.g. Thaler, 1987, qualitative reasoning, e.g. Selten, 2004, prominence, e.g. Schelling, 1960, and Albers, 2001, the Weber-Fechner law when perceiving numerical stimuli and when determining numerical choices etc.).

In our view, there is such an abundance of ideas that it would be presumptuous to claim being aware of and reviewing them all. Unlike Gigerenzer and Todd (1999), who seem to claim by speaking of ecological rationality that all or most of our heuristics are quite adequate, we do not think that this has been convincingly demonstrated. Except for some clearly irrational modes of behavior, e.g. leaving money idle in the financial investment task (section 4), most decision modes can be adequate for certain classes of decision tasks and quite inappropriate for others. The empirical proof of ecological rationality would require that heuristics are only used when adequate which is a much more demanding empirical exercise than those we have seen so far. ${ }^{6}$

In our view, this possible inadequacy of our behavior suggests that truly behavioral economics does not rule out normative attempts to improve our decision making. By

\footnotetext{
${ }^{5}$ Actually, the state specificity of goal formation, as in prior-free optimality and satisficing, illustrated above, may be seen as a special form of mental accounting.

${ }^{6}$ The $1 / \mathrm{N}$ heuristic is a good example. It has been the traditional advice of bankers for private investors (1/3 in real assets, $1 / 3$ in bonds, $1 / 3$ in shares) but is nowadays completely discarded and also not experimentally confirmed (see, for instance, Güth, 2007).
} 


\section{Jena Economic Research Papers 2007-099}

teaching, learning, consulting experts, more adequately perceiving the decision task, asking and processing more or better information a lot can be gained. Of course, those receiving advice should neither be assumed to command unlimited analytical skills nor be viewed as single-minded and mechanically reacting to information feedback.

Some of these "truly behavioral" ideas are by their very nature quite rigorously defined, e.g. the $1 / \mathrm{N}$ or the take-the-best heuristic in the heuristics toolbox (Gigerenzer and Todd, 1999). Similarly, routines have to be rigorously defined to render them applicable. For other ideas like qualitative resemblance, when trying to import successful behavior from different but related choice tasks, or cognitive representation of new decision problems, formal theories with solid empirical foundations still have to be developed. In our view, the tremendous task of doing so does not justify propagating old methodology. Behavioral economics has to offer a truly behavioral perspective how actual decisions are made and how behavior can be improved by teaching, learning, and advice. So we better engage in developing methodologically new tools suitable for such an, however demanding, endeavor.

\section{Conclusions}

Neoclassical repairs in the sense of more complex motivational preferences in choice tasks undoubtedly enrich microeconomics which, in case of enterprises, mostly assumed profit maximization without paying proper attention to other motives like being better than one's competitors, trying to increase one's market share, labor force etc. So we do not object to but rather strongly welcome attempts to capture risk attitudes, e.g. via risk aversion, other regarding concerns, reciprocity inclinations, belief dependent payoffs as in "psychological" games, etc. But, in our view, this is a new development in neoclassical microeconomics and offers not true contribution to behavioral economics. Methodologically, there is nothing new in neoclassical or game theoretic studies which allow preferences to depend on all sorts of motivation and emotions. What we question is whether keeping up the traditional methodology, which at best provides an as-if interpretation, does justice to our desire and need to study, understand, and improve people’s choice behavior. 
Similarly, studying evolutionary and learning dynamics is most welcome and very much needed. There exists now a much richer toolbox of adaptive dynamics which have been thoroughly explored, both theoretically and empirically. But although, in our view, decision making is a dynamic cognitive process (see Güth, 2000, for an attempt to outline such dynamics), its dynamics combines different adaptive processes like mental modeling, aspiration formation and adaptation, searching for satisficing choice alternatives, and retrospective evaluation of past choices in the light of feedback information. Simply assuming and analyzing just one constantly used adaptation is undoubtedly a valuable contribution to the field of economic dynamics but at best only providing some direction of what to expect when combining these different kinds of adaptations. Truly behavioral economics will have to come up with its own ideas of how different adaptive processes are combined and how people make up their mind what to do in a given choice task.

Such criticism would be rather futile when offering no alternative. We have briefly presented (a specification of) the satisficing approach, the core concept of bounded rationality theory. There is much more on offer if we more seriously pay attention to the behavioral tradition in economic, social, cognitive,... psychology what we have tried to indicate in section 5. As illustrated for the satisficing approach, these approaches can be more rigorously defined to derive definite predictions. Such specifications will, of course, have to be revised when it is poorly confirmed empirically. We also have argued that satisficing combines various sub-processes in the sense that after mental modeling, one may, for instance, form aspirations which one will adapt when searching more or less successfully for choice alternatives satisfying them. Defining and combining such dynamics, based on stylized facts, is an enormous challenge but rather than shying away from it, e.g. by using inadequate tools, we better give it a try! Why do economists, who do not want to use a truly behavioral approach, propagate the behavioral economics program?

\section{References}


Albers, W., 2001: Prominence Theory as a Tool to Model Boundedly Rational Decisions, in G. Gigerenzer and R. Selten (eds.), Bounded rationality: The Adaptive Toolbox, MIT Press.

Avrahami, J., Güth, W. and Y. Kareev, 2001: Predating predators: An Experimental Study, Homo Oeconomicus XVIII(2), 337-352.

Avrahami, J., Güth, W. and Y. Kareev, 2005: Games of Competition in a Stochastic Environment, Theory and Decision 59, 255-294.

Bazerman, M.H., Loewenstein, G. and L. Thompson, 1989: Social Utility and Decision Making in Interpersonal Contexts, Journal of Personality and Social Psychology 57(3), 426-441.

Berninghaus, S., Güth, W. and H. Kliemt, 2003: From teleology to evolution: Bridging the gap between rationality and adaptation in social explanation, Journal of Evolutionary Economics, 13(4), 2003, 385-410.

Berninghaus, S., Güth, W., Levati, M.V. and J. Qiu, 2006: Satisficing in sales competition: experimental evidence, working paper series of the Max Planck Institute of Economics Jena \# 32-2006.

Binmore, K. and A. Shaked, 2007: Experimental Economics: Science or What? Working paper \# 263.

Bolle, F., 1979: Das Problem des optimalen Stoppens (Doctoral dissertation, University of Hamburg, Germany), PhD thesis, University of Hamburg Germany.

Bolton, G., 1991: A comparative model of bargaining: Theory and evidence, American Economic Review, 81, 1096-1136.

Bolton, G. and A. Ockenfels, 2000: ERC: A theory of equity, reciprocity and competition, American Economic Review, 90, 166 - 193.

Bush, R.R. and F. Mosteller, 1951: A Mathematical Model for Simple Learning. Psychology Review, 58, 313-323.

Camerer, C.F., 2003: Behavioral Game Theory, Russell Sage Foundation, New York, New York/Princeton University Press, Princeton, New Jersey.

Cournot, A., 1938: Recherche sur les principes mathématiques de la théorie des richesses. Macmillan, New York.

Cyert, R. and J. March, 1964: A Behavioral Theory of the Firm, American Economic Review 54(2), 144-148. 
Dittrich, D.A.V., Güth, W., Kocher, M and P. Pezanis-Christou, 2005: Loss aversion and learning to bid, working paper series of the Max Planck Institute of Economics Jena \# 032005.

Fehr, E. and K.M. Schmidt, 1999: A Theory of Fairness, Competition, and Cooperation," The Quarterly Journal of Economics, MIT Press, vol. 114(3), 817-868.

Gigerenzer, G., 2000: Prominence Theory as a Tool to Model Boundedly Rational Decisions, in: G. Gigerenzer, R. Selten (eds.): Bounded Rationality: The Adaptive Toolbox, MIT Press.

Gigerenzer, G. and P. Todd, 1999, Simple heuristics that make us smart, in G. Gigerenzer, P. Todd (eds.), Oxford University Press.

Güth, W., 1995: On ultimatum bargaining - A personal review, Journal of Economic Behavior and Organization, 27, 329-344.

Güth, W., 2000: Boundedly rational decision emergence - a general perspective and some selective illustrations, Journal of Economic Psychology, 21, 433-458.

Güth, W., 2007: Satisficing in Portfolio Selection - Theoretical Aspects and Experimental Tests, Journal of Socio-Economics, 36, 505-522.

Güth, W., 2007: A Non-Bayesian Approach to (Un)Bounded Rationality, working paper series of the Max Planck Institute of Economics and Friedrich Schiller University of Jena, JERP \#2007-035.

Güth, W., Levati, M.V. and M. Ploner, 2007: Scenario-Based Satisficing in Saving: A Theoretical and Experimental Analysis, working paper series of the Max Planck Institute of Economics and Friedrich Schiller University of Jena, JERP \#2007-049.

Güth, W., Martin, E. and T. Weiland, 2006: Aspiration formation and satisficing in isolated and competitive search, working paper series of the Max Planck Institute of Economics Jena \# 26-2006.

Güth, W., Schmittberger, R. and B. Schwarze, 1982: An experimental analysis of ultimatum bargaining, Journal of Economic Behavior and Organization 3(4), 367-388.

Güth, W., Schmidt, C. and M. Sutter, 2003: Fairness in the Mail and Opportunism in the Internet: A Newspaper Experiment on Ultimatum Bargaining, German Economic Review, 4(2), 243-265.

Güth, W., Schmidt, C. and M. Sutter, 2007: Bargaining Outside the Lab - A Newspaper Experiment of a Three-Person Ultimatum Game, The Economic Journal 117, 449-469.

Hammerstein, P. and R. Selten, 1994: "Game theory and evolutionary biology," Handbook of Game Theory with Economic Applications, in: R.J. Aumann \& S. Hart 
(ed.), Handbook of Game Theory with Economic Applications, edition 1, volume 2, chapter 28, pages 929-993 Elsevier.

Homans, G.C., 1961: Social Behavior: Its Elementary Forms, Wiley, New York.

Huck, S., Normann, H.T. and J. Oechssler, 1999: Learning in Cournot Oligopoly: An Experiment, The Economic Journal 109, C80-C95.

Huck, S., Normann, H.T. and J. Oechssler, 2000: Does Information about Competitors' Actions Increase or Decrease Competition in Experimental Oligopoly Markets?”, International Journal of Industrial Organization 18, 39-57.

Mc Kelvey, R.D. and T. R. Palfrey, 1995: Quantal Response Equilibria for Normal Form Games, Games and Economic Behavior 10, 6-38.

Nash, J.F. 1950: Equilibrium points in n-person games. Proceedings of the National Academy of Science USA, 36, 48-49.

Ockenfels, A. and R. Selten, 2005, Impulse Balance Equilibrium and Feedback in First Price Auctions, Games and Economic Behavior, 51, 155-170.

Roth, A. and I. Erev, 1999: On the Role of Reinforcement Learning in Experimental games: The Cognitive Game-Theoretic Approach, in: D. Budescu, I. Erev, and R. Zwick (eds.), Games and Human Behavior: Essays in Honor of Amnon Rapoport, Mawhaw: Lawrence Erlbaum Associates, 53-77.

Rubinstein, A., 1998: Modeling Bounded Rationality, MIT Press.

Seale, D. and A. Rapoport, 1997: Sequential decision making with relative ranks: An experimental investigation of the secretary problem, Organizational Behavior and Human Decision Processes 69, 221-236.

Seale, D. and A. Rapoport, 2000: Optimal stopping behavior with relative ranks: The secretary problem with unknown population size, Journal of Behavioral Decision Making 13, 391-411.

Samuelson, L., 2001: Introduction to the Evolution of Preferences, Journal of Economic Theory 97, 225-230.

Samuelson, P., 1938: A Note on the Pure Theory of Consumers' Behaviour, Economica 5, 61-71.

Sauermann, H. and R. Selten, 1962: Anspruchsanpassungstheorie der Unternehmung, Zeitschrift für die gesamte Staatswissenschaft, 118, 577-597.

Schelling, T.C., 1960: The Strategy of Conflict, Cambridge: Harvard University Press. 
Selten, R., 2004: Boundedly Rational Qualitative Reasoning on Comparative Statics, 1-8, in: Steffen Huck (ed.), Advances in Understanding Strategic Behavior, Game Theory, Experiments and Bounded Rationality, Palgrave Macmillan, Basingstoke.

Selten, R. and J. Buchta, 1994: Experimental Sealed Bid First Price Auctions with Directly Observed Bid Funtions, in: D. Budescu, I. Erev, R. Zwick (eds.), Games and Human Behavior, Kluwer Academic Publishers, 79-102.

Selten, R. and W. Güth, 1982: Equilibrium point selection in a class of market entry games, in: Games, economic dynamics, and time series analysis - A symposium in memoriam Oskar Morgenstern - (eds. M. Deistler, E. Fürst und G. Schwödiauer), Wien, 101-116.

Simon, H., 1955: A Behavioral Model of Rational Choice, Quarterly Journal of Economics, 69, 99-118.

Thaler, R., 1987: The Psychology of Choice and the Assumptions of Economics, in: Alvin E. Roth (ed.), Laboratory Experimentation in Economics, Cambridge: University Press, 99-130.

Varian, H., 1992: Microeconomic Analysis, Third Edition, New York: Norton, Section 8.7.

Vega-Redondo, F., 1997: The evolution of Walrasian behavior, Econometrica 65, 375384.

de Waal, F., 2000: Chimpanzee Politics: Power and Sex among Apes. Baltimore: Johns Hopkins University Press.

Weibull, J., 1995: Evolutionary Game Theory, MIT Press. 